\title{
Don't Fake It, Make It! Technology and Tools for Virtual Hosts ${ }^{1}$
}

\author{
Jarred A. Shellhouse, Lauri M. Baker, Anissa Zagonel, Phillip Stokes, and Cheryl R. Boyer ${ }^{2}$
}

\section{Introduction}

The Don't Fake It, Make It! series assists virtual conference and meeting hosts in creating an engaging program to benefit their participants. Because many software possibilities exist to aid in hosting virtual events and creating engaging virtual experiences, this publication gives an overview of common features hosts look for in virtual conference software platforms before committing to one. While the focus of this document is on large online conferences or meetings with 50 or more participants, the content can be scaled to smaller virtual spaces. Event planners can use this document as a starting point to narrow down options. Once a host determines the technology to use for their virtual conference or meeting, they should do some individual research to ensure the selected software has all the needed features to conduct a successful program.

To begin a discussion about technology and tools available for hosting virtual conferences or meetings, first consider the participants and their needs. An online conference will have participants from all different levels of comfort and experiences using technology. The COVID-19 pandemic has forced some people who would not have previously selected to participate virtually into using online modalities (Vogels, 2020), but hosts should prepare to meet the needs of all participants, no matter their experience with technology.

\section{Virtual Participants}

Online conferences and meetings consist of presenters and participants who interact synchronously and/or asynchronously using internet-based platforms (Anderson \& Anderson, 2010) where members often take on one of the following roles (Figure 1):

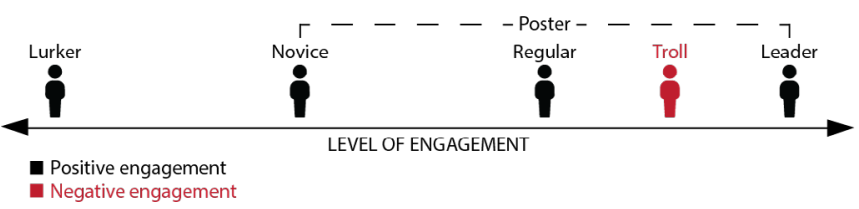

Figure 1. Level of engagement in online community members by role. Credits: UF/IFAS

- Lurkers. Lurking is often the first role someone will take in an online environment. They watch others participate in the event, but they do not contribute informationsharing or social engagement with others (Nimrod, 2012). Participants new to online events, like those forced online due to a pandemic, may feel most comfortable in this role. Lurkers may not feel as comfortable using the technology and tools as participants taking on other roles. While opinions of lurkers have gradually become more positive, they should be considered as stakeholders in online learning because they benefit from knowledge that is shared, even if they do not share it directly with others (Nguyen, 2020).

1. This document is AEC729, one of a series of the Department of Agricultural Education and Communication, UF/IFAS Extension. Original publication date May 2021. Visit the EDIS website at https://edis.ifas.ufl.edu for the currently supported version of this publication.

2. Jarred A. Shellhouse, marketing specialist; Lauri M. Baker, associate professor, Department of Agricultural Education and Communication; Anissa Zagonel, research and marketing associate, Center for Rural Enterprise Engagement; Phillip Stokes, learning and organizational development specialist, Center for Public Issues Education in Agriculture and Natural Resources; and Cheryl R. Boyer, associate professor, Department of Horticulture \& Natural Resources, Kansas State University; UF/IFAS Extension, Gainesville, FL 32611.

The Institute of Food and Agricultural Sciences (IFAS) is an Equal Opportunity Institution authorized to provide research, educational information and other services

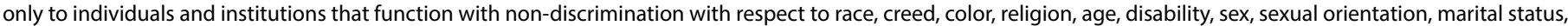

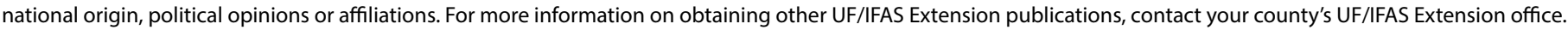
U.S. Department of Agriculture, UF/IFAS Extension Service, University of Florida, IFAS, Florida A \& M University Cooperative Extension Program, and Boards of County Commissioners Cooperating. Nick T. Place, dean for UF/IFAS Extension. 
- Novices. In this role, participants may start to engage with others and share information on a few topics but remain in a passive role the majority of time (Nimrod, 2012). An increase in engagement and comfort level occurs for novices because they typically have more experience with technology in general and the tools specific to the meeting or conference.

- Regulars. These members are well established in the online community and communicate regularly and efficiently (Nimrod, 2012). Regulars are more engaged and more comfortable with technology, and they can usually be seen communicating and engaging in multiple ways (e.g., chat features, polling, follow-up emails).

- Leaders. This group often takes an active role in shaping the community dynamics, which sometimes includes orienting new members (Nimrod, 2012). There may be an opportunity to leverage these users to help engage lurkers and novices in your meeting or conference.

- Posters. Those classified as novice, regular, or leader all fall into a category of poster, in which they contribute to social engagement and information sharing in some capacity.

- Trolls. Individuals (humans or bots) in this group are a type of poster, but they only participate with the goal to disrupt the online environment by producing a large amount of information for a short period of time to disturb the community members, or by sharing inappropriate content to the group (Sonnenbichler, 2009). Some bots are programmed to disrupt online spaces and can repeatedly post content, inject viruses into online spaces, or create other interruptions to interfere with the online conference or meeting or absorb confidential information. When selecting software for use in your meeting or conference, it is important to consider which features are available to enhance security and limit trolls.

The discussion below focuses on creating an effective community for both posters and lurkers, because previous literature has suggested passive users (lurkers) may feel a similar sense of belonging to those with more frequent posting and participation behavior (Gibbs et al., 2019). We also include ways to minimize the disturbance of trolls.

\section{Hosting Platforms}

Many platforms exist to host video conferences and meetings with various features and different price points. Each of these pose benefits and challenges that should be fully explored before committing to software to host a virtual conference or meeting. Table 1 compares much of the available hosting software, though the list is not exhaustive.
Additionally, these programs continuously go through updates, which can give them additional features. The table reflects software features available in November 2020. The categories for the table are explained below.

- Meeting or Conference? This section indicates whether the software is best utilized for (a) virtual meetings, (b) virtual conferences and webinars, or (c) both. See Baker et al. (2020) for additional information regarding the difference between meetings and conferences.

- Live Video Call Option: This table category refers only to the availability of a feature where hosts and participants can engage with each other through live video calls. While some software allows the host to livestream the call to other social media platforms (such as Facebook or YouTube), this category in Table 1 only acknowledges whether or not a live video call can be placed within the software.

- Recording Option: The recording option section refers to the availability of the software to record a live video call or for the host to record a video, which can be shared with participants later.

- Chat Feature: The chat feature indicates whether participants are able to type messages to each other or to the host through Q\&A chat, open or private discussions, or asynchronous messaging (occurring outside of the live video chat).

- Polling Feature: This section indicates whether the host is able to deploy polls to the users on a call or otherwise survey the participants. All software that indicates polling is available also allows the host to share the polling results with the participants live during the call.

- Breakout Rooms/Grouping: The grouping section indicates software that can break up the entire group on the call into smaller sections, allowing for more productive discussion among fewer people or about a specific content area.

- Security: Data encryption and decryption are important to consider. When on a video call, the audio and video that is transmitted through the internet is coded to make it less likely for hackers to intercept the information. When privileged or confidential information is discussed through the call, higher levels of encryption and decryption are needed. The main security levels indicated in the table are explained below.

- FedRAMP. For US federal government data sharing.

- FERPA. For education data, specific to student records and other identifiable, confidential information. 
- GLBA. For sharing data related to private financial information.

- HIPAA. Data sharing of private medical information.

- ISO 27001. For security of digital information, such as video and audio.

- SOC. For security against cybersecurity attacks.

- AES-256 (or 128). Advanced encryption standard for 256 (or 128) bit digital information, protecting sensitive data.

- End-to-End Encryption. Data is encrypted from the sender and not decrypted until the receiver gets it. This means the data remains encrypted while it is stored or passing through the servers of the specific software company.

- In-Transit Encryption. Data is only encrypted while being sent from one person to another. Therefore, it is decrypted for the receiver, but it also remains on the servers for the software company in decrypted form.

- Cost: The cost indicates the price of the subscription plan. The price reflects the number of participants allowed on a call/video, but it may also include additional features not available on the table. It should be noted that the University of Florida (UF) has licenses for some of the listed software, which all campus and statewide faculty can access. One should check with their institution and campus to see which of these may be available for use within their system or unit, because access may vary.

- Max Number of Participants: This section indicates how many users (hosts and participants) can be on the video call per each price point.

\section{Limiting Trolls}

Selecting a platform with strong security features can protect your data and limit random trolls, but you can also work to limit access for trolls by how you set up a virtual meeting or conference.

- Enable a waiting room feature. This would require the host to allow participants into the room. It works in a similar way in which a person could show up to an in-person meeting and knock, but they would not be let into the room until the host unlocks and opens the door.

- Require advanced registration. Using this feature, participants are not given the hyperlink to the event until close to the start of the meeting or conference. Many trolls gain access to meeting links ahead of the event and make a plan to join and share content that is inappropriate or interrupt speakers. When links are not publicized ahead of time, trolls' access is limited to a much smaller window of time.

- Limit participants' access to tools and features within the platform. For example, when hosting a conference with a controversial speaker, it may be wise to limit participants' questions to a question-and-answer feature seen only by the hosts/panelists, or to mute all participants and limit their ability to share screens. The limitations for participants vary by software.

- Require participants to enter passwords, and do not publish the passwords to your event in open online spaces, such as social media. Instead, share the password in a workbook mailed to participants ahead of time, email it directly with a calendar invitation, or share it using an internal communication method used by the hosting company.

\section{- Designate someone within your team to mute or eject trolls as quickly as possible.}

\section{File Sharing}

Outside of the synchronous (live) or asynchronous (recorded) video elements of a virtual meeting or conference, it may be important for the host to share additional files with the participants. Some software, like Microsoft Teams or Slack, allows the user to share files and other information directly in the software, ensuring that all participants with access to the video call can obtain the additional files before, during, or after the video call. However, other software (e.g., Zoom) only allows the participants to share files during the live call. If the host plans to send workshop materials beforehand or give slides and notes to participants afterward, it would be beneficial to look into file-sharing sources like Dropbox or Google Drive.

\section{Conclusion}

Before committing to software for a virtual meeting or conference, hosts should closely examine their audience and their needs. When selecting software, it is important to consider subscription plan prices, available features, ADA compliance needs, and how technologically savvy their audience is. Many software companies allow for demos and free trials, which are strongly suggested for hosts to determine if the software is user-friendly enough to allow participants to have a pleasant virtual experience without battling technology for the duration. Table 1 outlines the features and pricing collected from a variety of available software but should not be regarded as an exhaustive list. 
Once the host has narrowed down their options, they should once again consider the audience and make a final determination based on the level of commitment and contribution they want from their participants.

\section{References}

Anderson, L., \& Anderson, T. (2010). Online conferences: Professional development for a networked era. Information Age Publishing.

Baker, L. M., Benge, M. P., Zagonel, A., Shellhouse, J. A., Boyer, C. R., \& Stokes, P. (2020). Don't fake it, make it! Thriving in virtual conferences and meetings. EDIS, 2020(4). https://doi.org/10.32473/edis-wc365-2020

Gibbs, J. L., Kim, H., \& Seol, K. (2019). Investigating the role of control and support mechanisms in members' sense of virtual community. Communication Research, 46(1), 117-145. https://doi.org/10.1177/0093650216644023

Nguyen, T. M. (2020). Four-dimensional model: A literature review on reasons behind lurking behavior. VINE Journal of Information and Knowledge Management Systems. https://doi.org/10.1108/VJIKMS-10-2019-0168

Nimrod, G. (2012). The membership life cycle in online support groups. International Journal of Communication, 6, 23. https://link.gale.com/apps/doc/A294901480/LitRC?u $=$ gain $40375 \&$ sid $=$ LitRC\&xid $=687 \mathrm{e} 719 \mathrm{c}$

Sonnenbichler, A. C. (2009). A community membership life cycle model. Proceedings of the International Network for Social Network Analysis (INSNA): Sunbelt Conference. http://arxiv.org/PS_cache/arxiv/pdf/1006/1006.4271v1.pdf

Vogels, E. A. (2020). From virtual parties to ordering food, how Americans are using the internet during COVID-19. Pew Research Center. https://www.pewresearch.org/facttank/2020/04/30/from-virtual-parties-to-ordering-foodhow-americans-are-using-the-internet-during-covid-19

\section{Appendix}

1. Don't Fake It, Make It! Thriving in Virtual Conferences and Meetings

2. Applying Learning Theory to Virtual Conference Spaces

3. Am I Ready? Competencies and Skill Sets Needed for Virtual Conference Hosts

4. Technology and Tools for Virtual Hosts

5. Let's Do This Right: Best Practices for Hosting Virtual Conferences

6. Host with the Most: Best Practices for Hosting Virtual Meetings

7. Best Practices for Hosting Virtual Webinars

8. Best Practices for Hosting Virtual Events and Fairs

9. Best Practices for Attending Virtual Events 


\begin{tabular}{|c|c|c|c|c|c|c|c|c|c|c|c|c|}
\hline 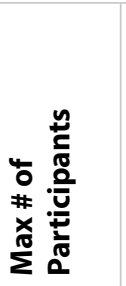 & 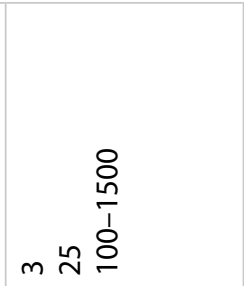 & $\tilde{m}$ & 응 음 & ঃั ৪ ঃ ঃ & in in & 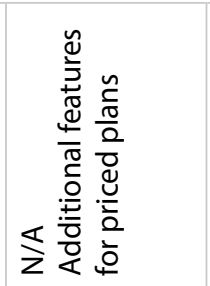 & ঃ ঃ & in & $\stackrel{\Perp}{\sim}$ & 윰요 & ঃ 윳 : & 훙 ৪ \\
\hline 范 & 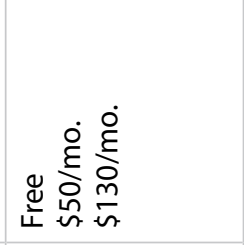 & 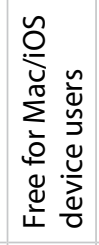 & 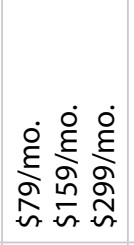 & 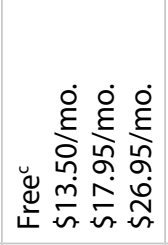 & 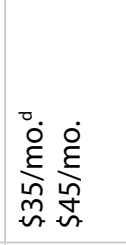 & 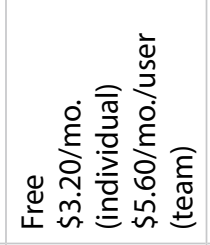 & 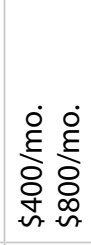 & 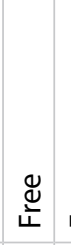 & 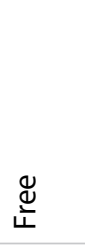 & 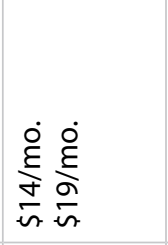 & 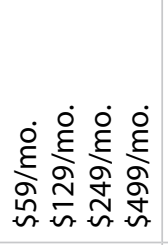 & 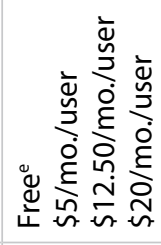 \\
\hline : & 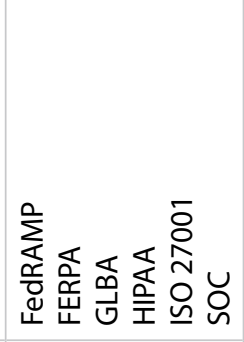 & 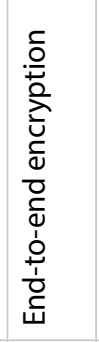 & 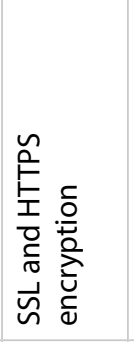 & 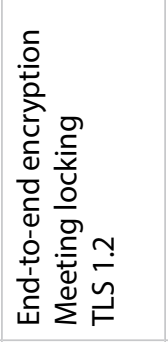 & 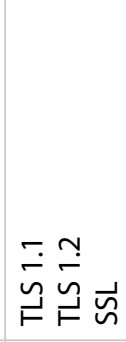 & 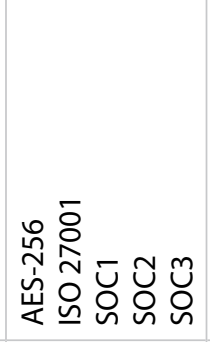 & $\begin{array}{l}\frac{5}{3} \\
0 \\
\frac{c}{5} \\
\frac{5}{5}\end{array}$ & 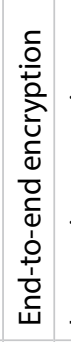 & 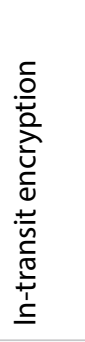 & 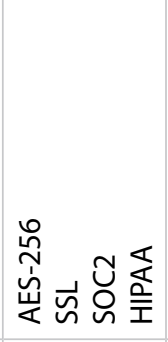 & 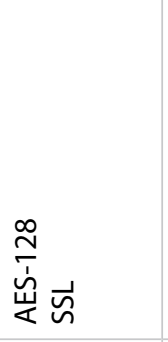 & $\begin{array}{l}\frac{5}{3} \\
0 \\
\frac{5}{5} \\
\text { c }\end{array}$ \\
\hline 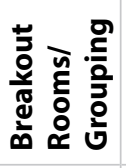 & $\stackrel{y}{\nu}$ & $\frac{0}{2}$ & $\begin{array}{l}\frac{5}{3} \\
0 \\
\stackrel{5}{5} \\
\text { ș }\end{array}$ & $\stackrel{\check{\Perp}}{\nu}$ & 울 & 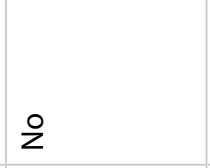 & 을 & $\stackrel{\stackrel{y}{\tilde{y}}}{\nu}$ & $\stackrel{0}{z}$ & z & ㅇ & $\stackrel{\stackrel{y}{y}}{\nu}$ \\
\hline 일 & $\stackrel{\check{\nu}}{\check{\nu}}$ & $\frac{0}{2}$ & $\stackrel{\breve{\nu}}{\nu}$ & $\stackrel{\breve{y}}{\nu}$ & 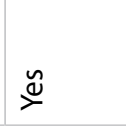 & 2 & $\stackrel{\mathscr{y}}{\check{\nu}}$ & $\stackrel{\tilde{\nu}}{\check{\nu}}$ & ㄹ & 2 & $\stackrel{\tilde{\nu}}{\rightleftharpoons}$ & z \\
\hline 竞 & $\stackrel{\check{\Perp}}{\check{N}}$ & $\frac{0}{2}$ & $\stackrel{\breve{\Perp}}{\check{\nu}}$ & $\stackrel{\breve{\Perp}}{\nu}$ & $\stackrel{\check{\nu}}{\check{\Perp}}$ & 2 & $\stackrel{\breve{\Perp}}{\nu}$ & $\stackrel{\oiiint}{\check{\Perp}}$ & 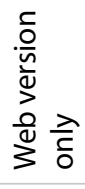 & $\stackrel{y}{\nu}$ & $\stackrel{\check{\nu}}{\nu}$ & $\stackrel{y}{\nu}$ \\
\hline 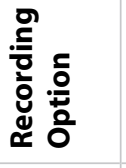 & $\stackrel{\check{\Perp}}{\check{\nu}}$ & $\frac{0}{2}$ & $\stackrel{\breve{u}}{\nu}$ & $\stackrel{\breve{y}}{\nu}$ & $\stackrel{\mathscr{\nu}}{\check{\nu}}$ & $\stackrel{\check{\nu}}{\check{\nu}}$ & $\stackrel{\tilde{\nu}}{\check{\nu}}$ & $\frac{0}{z}$ & $\stackrel{0}{z}$ & $\stackrel{\check{y}}{\check{\nu}}$ & $\stackrel{\tilde{\nu}}{\nu}$ & $\stackrel{\ddot{y}}{\check{x}}$ \\
\hline 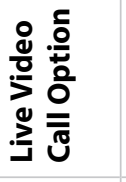 & $\stackrel{\check{\nu}}{\check{1}}$ & $\stackrel{\check{\Perp}}{\check{\nu}}$ & $\stackrel{\breve{u}}{\rightleftharpoons}$ & $\stackrel{\breve{u}}{\rightleftharpoons}$ & $\stackrel{\breve{y}}{\succ}$ & z & $\stackrel{y}{\nu}$ & $\stackrel{\check{y}}{\nu}$ & $\stackrel{\tilde{\nu}}{\nu}$ & $\stackrel{\breve{y}}{\succ}$ & $\stackrel{\breve{\nu}}{\nu}$ & $\stackrel{\breve{u}}{\rightleftharpoons}$ \\
\hline 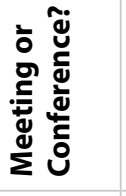 & $\begin{array}{l}\text { F્ } \\
\text { ○ }\end{array}$ & 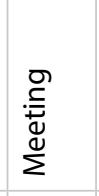 & 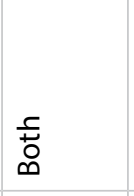 & 善 & 善 & $\begin{array}{l}\text { Fे } \\
\text { 总 }\end{array}$ & 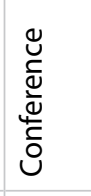 & 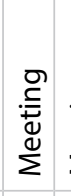 & 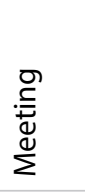 & 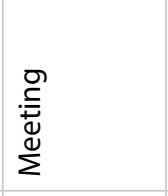 & 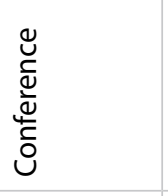 & $\begin{array}{l}\text { Fे } \\
\text { ○े }\end{array}$ \\
\hline 选 & 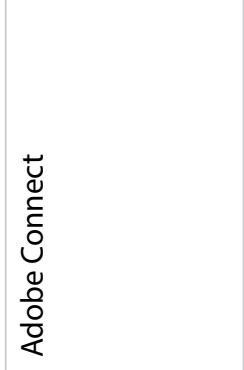 & 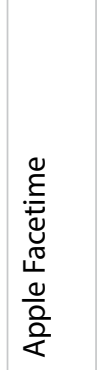 & 㐫 & 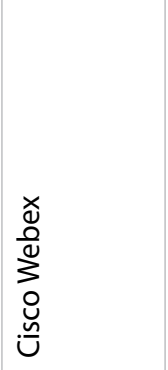 & 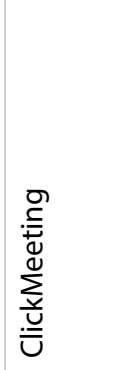 & $\begin{array}{l}\frac{0}{2} \\
\frac{0}{0} \\
\frac{0}{U} \\
\text { U }\end{array}$ & 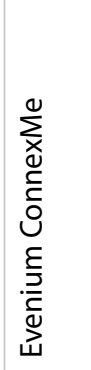 & 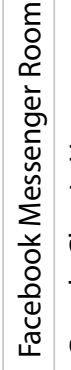 & 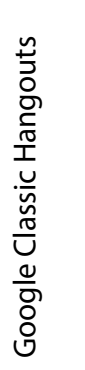 & 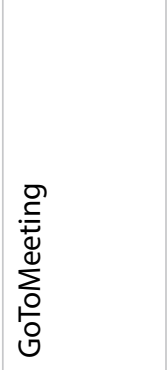 & 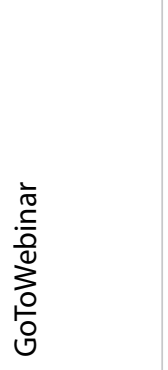 & 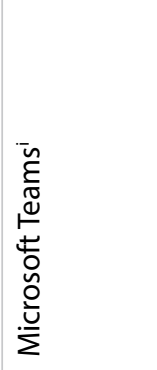 \\
\hline
\end{tabular}




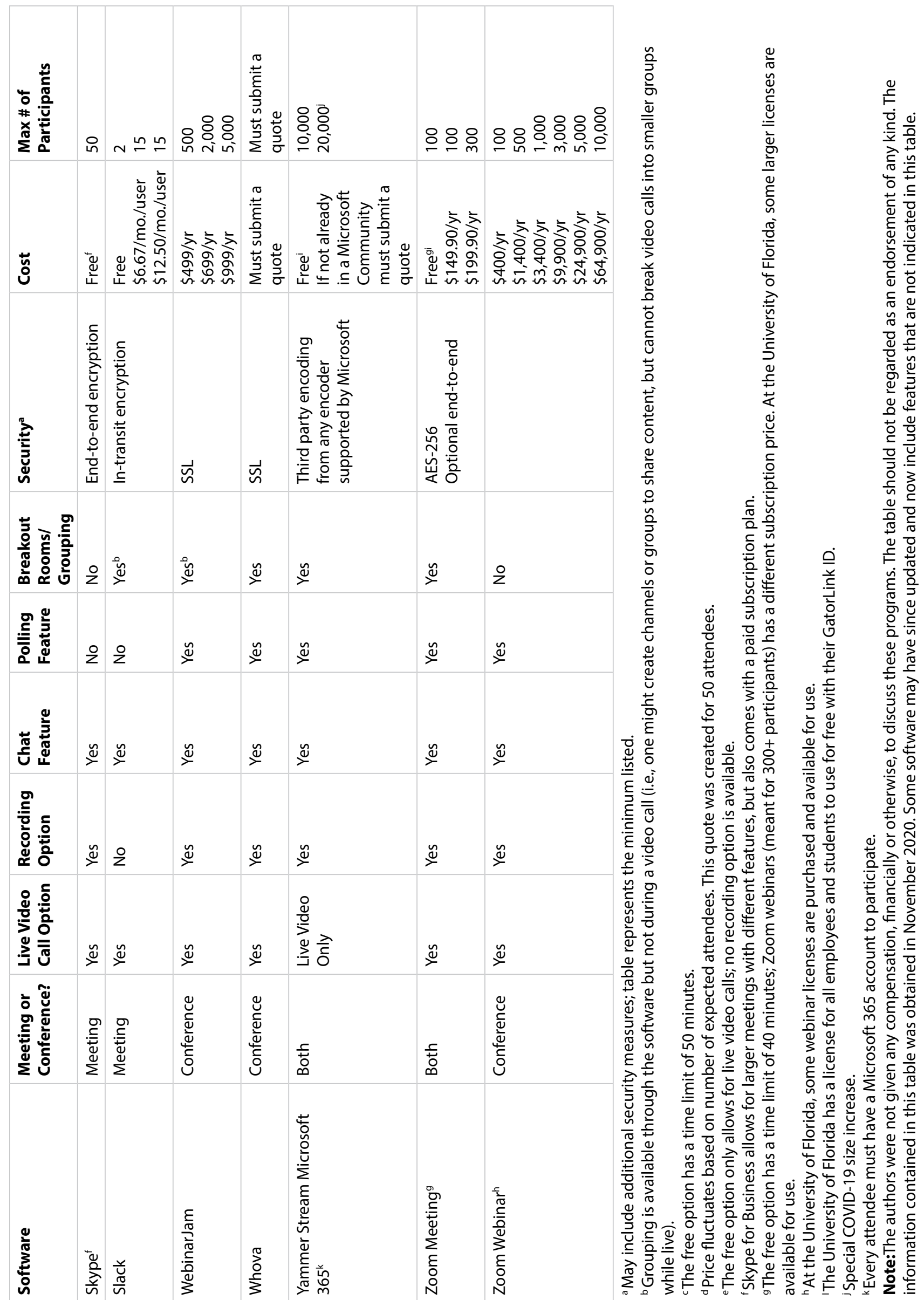

